Ruth Dassonneville

Yves Dejaeghere

\title{
Bridging the Ideological Space. A Cross-National Analysis of the Distance of Party Switching
}

\author{
European Journal of Political Research, accepted
}

\begin{abstract}
Scholars have investigated the characteristics of volatile voters ever since the first voter surveys were carried out and they have paid specific attention to the role of political sophistication on vote switching. Nevertheless, the exact nature of this relationship is still unclear. With increasing volatility over the past decades this question has furthermore grown in relevance. Is the growing unpredictability of elections mostly driven by sophisticated voters making well-considered choices or is the balance of power in the hands of unsophisticated 'floating voters'? Several scholars have argued that even under conditions of increasing volatility switching is still mostly confined to changes to ideologically close parties. Most researchers, however, have used rather crude measures to investigate this 'leap' between parties. To advance research in this field we suggest to directly take into account the ideological distance bridged by volatile voters when investigating the link between political sophistication and volatility. We do this using CSES-data that encompasses a broad sample of recent parliamentary elections worldwide. Results indicate that voters with an intermediate level of political knowledge are most likely to switch overall. When taking into account the ideological distance of party switching, however, the confining impact of political knowledge on the vote choices made is clearly dominant, resulting in a linear decrease of the distance bridged as voters.
\end{abstract}

Keywords: Comparative politics; Volatility; Left-Right position 


\section{SUMMARY}

\section{INTRODUCTION}

It only took a few years after Lipset and Rokkan's (1967) seminal publication on the frozenness of European party systems for scholars to point at patterns of growing electoral instability. Looking at the shifts in vote shares between one election and another they indicated that electoral volatility was clearly rising (Pedersen, 1979, Crewe and Denver, 1985). This was challenging for the classical theories of voting behaviour that stress the importance of social cleavages and hence stability. Bartolini and Mair did concede that large electoral changes occurred, but contended in defense of cleavage theory that (1990, p. 36): “. .

. the volatility which matters in terms of cleavage persistence or change is the volatility which occurs between blocks of parties representing the opposing side of a cleavage line." It is generally assumed that voters who switch to an ideologically close party are driven by rational considerations. Volatile voters are still thought to be bounded by ideological considerations and to make a structured choice (van der Meer et al., 2012). Additionally, switching to parties within an ideological block is often interpreted as driven by strategic considerations (Lachat, 2007). Voters switching between blocks, on the other hand, do not seem to be taking ideology into account when voting. These floating voters are described as "electoral drifters or rolling stones, who cast their vote almost at random" (Katz, Rattinger and Pedersen, 1997, p. 87). It is clear that for Bartolini and Mair (1990) only the evolution of the latter was relevant regarding the validity of cleavage theory. Such an approach has since become widely accepted. In aggregate-level as well as in individual-level research, scholars therefore regularly distinguish between voters who change parties within an ideological block on the one hand and voters changing blocks on the other (Lachat, 2007, Kuhn, 2009, van der Meer et al., 2013). Scholars have shown that most switching does occur within ideological blocks of parties. As such, even in a highly volatile context as the Dutch electoral sphere, volatility has been described as bounded (van der Meer et al., 2012). Clearly, when looking at volatility, degrees of switching have to be taken into account.

It is clear that the differentiation between two kinds of switching has implications for the formulation of hypotheses regarding the relation between political sophistication and volatility. Although it is an old issue in the field of electoral behaviour, the question whether political sophistication increases or decreases vote switching is still unclear and intensely 
debated. We aim to gain new insights in the causal link between political sophistication and party switching by explicitly taking into account the aspect of ideological distance.

In this paper the ideological distance of party switching will be analysed comparatively by focusing on parliamentary elections in democratic countries worldwide. The data come from the second and third module of the Comparative Study of Electoral Systems (CSES)-project. We start with a review of the literature on volatility and block-volatility more specifically. Next, we elaborate on the scholarly debate on the link between political sophistication and vote switching. We then describe the data and the methods used, after which we present the results. We end with some concluding remarks on the implications of our findings and limitations of the current paper.

\section{TOTAL VOLATILITY AND BLOCK VOLATILITY}

Mogens Pedersen (1979) was one of the first scholars to draw attention to a process of change in electoral behaviour. Looking at the increase of net volatility at an aggregate level, he argued that both voters and party systems were becoming increasingly volatile. This observation did not remain unchallenged and Peter Mair (1993) characterized the idea of electoral change as being largely mythical. One of his arguments was that even though electoral results might indeed have become slightly more volatile, most of the changes observed were still confined within ideological blocks. Mair (1993, p. 124) stated therefore: "looking at the aggregate evidence, it is readily apparent that when voters switch, they switch between friends rather than between enemies." To investigate the degree of switching 'between enemies' Bartolini and Mair (1990) modified the standard volatility measure into so-called "block volatility". Doing so one only considers a switch relevant when it is between parties belonging to different ideological blocks.

$(\ldots)$

\section{POLITICAL SOPHISTICATION: STIMULUS OR RESTRAINT FOR PARTY SWITCHING?}

Volatility as such is not problematic for a democracy and some level of party-switching actually reinforces the democratic credentials of an election (Blondel, 1968). Such a positive 
view on volatility relates to the normative stereotype of an "individual, educated, rational voter as the model citizen" that was passed on in western democracies since the Progressive Era (Schudson, 2000: 9). This is a voter who selects a party in an election after thoughtful consideration of different electoral platforms and not because she voted for this party 'the last time round'. If such a citizen switches parties, one can only laud her for the cognitive effort involved. This normative view of the citizen is one of the reasons that the most vibrant discussion in relation to electoral volatility has revolved around the question whether it is the low or the high sophisticated voters who are more likely to switch parties.

After having investigated vote intentions of American voters in the 1948 presidential election campaign, Berelson, Lazarsfeld and McPhee (1963) concluded that voters who switch vote intentions are lowly interested in politics. They consequently labeled voters who are switching parties as 'floating voters'. This thwarted the optimistic normative illusions on rational citizens and has led to a characterization of volatile voters having a low level of political sophistication. The implication of this perspective on volatile voters is that the uninterested voters hold the balance of power. This paradoxical and discomforting point of view has subsequently induced more research on the link between political sophistication and volatility (Converse, 1962, Boyd, 1986, Granberg and Holmberg, 1990). A number of scholars have argued that when looking into the data there is hardly any empirical evidence supporting the floating voter hypothesis (Converse, 1962, Daudt, 1961). Converse (1962) therefore suggested a modification of the floating voter hypothesis for campaign volatility. $\mathrm{He}$ argues that faced with political information, a dual process is at work. While the lower sophisticated are very susceptible to changing preferences, they are also very unlikely to perceive cues for change, rendering them more stable than originally thought. The higher sophisticated then, are more likely to perceive political information and are therefore more likely to switch preferences. As their level of sophistication increases, however, these voters become more and more resistant to change. This reasoning is very much in line with Zaller's (1992) findings on the link between political sophistication and information processing and leads to the expectation of a curvilinear effect of political sophistication on vote intention switching. The modification of Converse, however, was one for switching within a campaign only. As far as inter-election volatility is concerned, although Lazarsfeld, Berelson and Gaudet (1965) did not generalize their floating voter hypothesis to switching from one election to another, Converse (1962) argued that for this type of switching evidence is more clearly in line with the hypothesis of the least involved voters switching most. But in the same 
period Benewick et al. (1969) concluded their analyses of British panel data with: "the figures indicated that a substantial proportion of the floating voters were well-informed and interested in politics. " Leaving the discussion on this topic wide open.

Russell Dalton (1984), as well argues against the floating voter hypothesis. He asserts that since the publication of the early survey-based voter studies, the electorate has fundamentally changed. Through a process of societal change called cognitive mobilization, voters now have more cognitive capabilities and wider access to political information compared to voters in the 1940s and 1950s. As a consequence, current-day voters are no longer in need of partisanship as a vote-choice heuristic. Looking at the characteristics of voters in a number of western democracies, he argues that a growing group of highly sophisticated apartisans is now part of the electorate (Dalton, 2012, Dalton, 2013). These apartisans make their vote choices independent of party alignments and they are hence more volatile than partisans. Lachat (2007) has further built on this link between partisanship and volatility and he argues that predispositions are crucial to be taken into account when investigating the link between political sophistication and volatility. As for the effect of sophistication on volatility, Lachat argues that a curvilinear effect is to be expected, with most volatility among voters with a middle level of political sophistication. His argument, which can be found in the work of Kuhn (2009) as well, is based on research on information processing. The argument is basically the same as the modification that was proposed by Converse (1962) for investigating the impact of political involvement on campaign-switching. Research on priming effects has previously indicated that citizens who are highly attentive to political news are least likely to be swayed by media messages. The explanation given for this finding, is that these highly attentive citizens have well-developed political opinions based on an extensive amount of information. New information therefore only has a limited impact on these citizens' attitudes (Krosnick and Brannon, 1993). Similarly, Zaller (1992) has indicated that low informed voters are most responsive to election-specific influences. Well informed voters, on the other hand, have well developed political attitudes and quite often a strong party identification as well. As a result, campaign messages are only having a limited impact among this group. Previous research clearly indicates that as voters are exposed to political information, a dual process is at work. While political experts are more likely than political novices to perceive new information, they are also less likely to change accordingly. Originally suggested as an expectation on the short-term first and foremost, the expectation of curvilinear effects has been confirmed in a number of studies on campaign volatility (Boyd, 1986, Latimer, 1986). 
Lachat (2007) and Kuhn (2009), then, expect curvilinearity for both campaign- and interelection volatility. As a result, with regard to our analysis of inter-election volatility as well, we expect to find a nonlinear relationship with highest levels of volatility among voters with an intermediate level of political sophistication.

Hypothesis 1: The likelihood of switching parties from one election to another is highest among voters with an intermediate level of political sophistication.

Even though it seems obvious to take into account whether voters switch to ideologically close or distant parties when investigating the link between political sophistication and volatility, this has only rarely been done. Both Lachat (2007) and Kuhn (2009) do distinguish between within- and between-block switching in the German and/or Swiss context, but neither of them posits a different hypothesis for the effect of political sophistication on volatility for the two types of volatility. A nonlinear relationship is by both authors argued to be expected for within-block switching as well as for between-block switching. Looking at their results for switching from one election to another, a strong curvilinear pattern, with the middle sophisticated voters most likely to switch, can indeed be observed when switching between party blocks is considered. For within-block switching, the evidence does not suggest a curvilinear pattern, however. These contradictory results for both types of volatility have been interpreted as surprising and have led Kuhn (2009, p. 484) to assert that her results: "reveal however also the necessity to further reflect and investigate on the effect between political sophistication, particularly on the striking differences of between-and within-block changes."

Trying to explain the high likelihood of within-block switching among the high sophisticated in Germany, Lachat (2007) refers to the practice of strategic voting in the German electoral context. Strategic considerations are expected to be cognitively quite demanding and cues given by parties to enhance strategic voting as well are most likely to be perceived by political experts, hence the high presence of within-block switching among the high sophisticated. Additionally, Lachat (2007) indicates the asymmetry in political information between large and small parties as a source for high sophisticated voters' high likelihood of within-block switching. Given the relative scarcity of information on smaller parties, only high sophisticated voters can be expected to be exposed to this information and to subsequently switch to a small party within 'their' block. While not excluding the impact of strategic voting 
and information, we suggest that the ideological distance of parties within a party block is crucial in this regard. High politically sophisticated voters have previously been found to have better developed political attitudes than political novices (Zaller, 1992). Therefore, we expect that ideology is an important restraint for high politically sophisticated voters who switch parties, which can explain their high rate of within-block switching. We test the straightforward hypothesis that as voter's level of political sophistication increases, the ideological distance bridged from one election to another is smaller.

Hypothesis 2: The higher a voter's level of political sophistication, the smaller the ideological distance she bridges from one election to another.

\section{DATA AND METHODS}

\subsection{Data and Coding}

In order to test the hypotheses presented above, we need sufficient variation in the ideological distance bridged by voters switching parties from one election to another. Therefore, ideally, we make use of a sample of voters in a large number of modern democracies. For this purpose, we make use of the data provided by the Comparative Study of Electoral Systems (CSES)-project. Given that we are focusing on volatility at an individual level, we are confined to those surveys within the project that included a recall question on previous voting behaviour. Such a question was included from the second module of the CSES-project onwards, therefore the data used for the current analyses are from the second and third modules of CSES.

\section{$(\ldots)$}

\subsection{Measures}

Our main interest in this paper is assessing the impact of voters' level of political sophistication on the ideological distance they bridge from one election to another. Political sophistication is an abstract and complex concept in which not only knowledge, but also how individuals structure information is of central importance. When it comes to measuring political sophistication, different approaches have been suggested and are used by scholars 
(for an extensive overview see Lachat 2007). Political interest, media use, political involvement and levels of education are all linked to political sophistication and have been used as indicators of the concept. Reviewing the literature, however, several scholars have pointed out that political knowledge is the most direct and probably the best measure of political sophistication that can be used (Delli Carpini and Keeter, 1996, Lachat, 2007, Marthaler, 2008). Therefore, we make use of a measure of political knowledge as an indicator of voters' level of political sophistication. Most national election surveys conducted in the framework of the CSES-project contain three knowledge questions. These are designed in such a way by the national survey teams that questions are answered correctly by two thirds, half and one third of the respondents respectively (Grönlund and Milner, 2006). ${ }^{\mathrm{i}}$ Summing the number of correct answers on the three knowledge questions gives us for each respondent a score of political knowledge ranging between 0 and 3. Additionally, in order to take into account between-country variation in voters' political knowledge scores, we standardized the measure for political knowledge by dividing individuals' knowledge score by the average knowledge score in their election sample (Singh and Thornton, 2013). Doing so, the categorical measure of political knowledge is transformed into a continuous one.

\section{$(\ldots)$}

\subsection{Method}

The data have a hierarchical structure, with respondents nested in elections and these elections nested in countries. A number of different approaches can be used to take this nested structure into account. For the current analysis, given our interest in the general effect of political sophistication on vote switching, our focus is at the individual level only. Furthermore, there is a substantial amount of variation in electoral systems, political contexts and electionspecific factors across the elections sampled and all these factors can be argued to affect the degree of switching. In order to control for the potential impact of all of these contextual factors, we present the results of fixed effects models that include election-specific dummies. ${ }^{\text {ii }}$

\section{RESULTS}

As a first step, we investigate the relation between political knowledge and voters' likelihood of switching parties in general. Doing so, we do not take into account the ideological distance 
bridged or whether respondents switch to parties within or between blocks. Either a voter switches parties from one election to another or she doesn't, which is modeled in terms of a logit function.

The results of the analyses are presented in Table 3. In Model 1 only the main effect of political knowledge is included, Model 2 additionally includes its squared term, allowing to test for a curvilinear effect of political sophistication on party switching. Looking at the control variables, we can observe that as voters are older, they are less likely to switch parties from one election to another. There are no significant differences in the probability of switching for male and female voters, but college education is a significant predictor. As the results indicate, respondents holding a college degree are significantly more likely to report having switched parties. Results furthermore confirm previous evidence indicating that switching parties is an expression of political disaffection. As their level of satisfaction with democracy increases, respondents are less likely to report party switching. Similarly, as voters have a higher sense of political efficacy, they are less likely to switch parties from one election to another. Not surprisingly, the effect of being close to a particular party is strong and highly significant, a result which confirms the need to control for partisanship when investigating what determines volatility. The ideological distance to the party that is closest to the party previously voted for is not a significant predictor of party switching. Controlling for differences across the electoral contexts in the sample by means of fixed effects, we do not observe that being more close to an alternative party makes a voter more likely to switch parties from one election to another.

Our main interest is in the effect of political knowledge, which we use as a proxy for respondents' level of political sophistication, on volatility. As clear from Model 1, only including the main effect of political knowledge does not indicate a statistically significant effect of political knowledge on party switching. Additionally including the squared effect of knowledge in Model 2 does indicate a statistically significant effect of political knowledge on party switching. We observe a positive and significant effect of the main term and a significant negative effect of the squared term of knowledge. As such, these results do indicate a curvilinear effect of political sophistication on party switching. While Model 2 has a slightly better model fit compared to the first model, as evident from the somewhat lower AIC-value, it is equally obvious that the explanatory power of both models is rather low. 
Table 3. Explaining party switching

\begin{tabular}{|c|c|c|}
\hline & Model 1 & Model 2 \\
\hline & $\begin{array}{c}\mathrm{B} \\
\text { (s.e.) }\end{array}$ & $\begin{array}{c}\mathrm{B} \\
\text { (s.e.) }\end{array}$ \\
\hline Constant & $\begin{array}{c}0.819 * * * \\
(0.129)\end{array}$ & $\begin{array}{c}0.747 * * * \\
(0.141)\end{array}$ \\
\hline Age & $\begin{array}{c}-0.013 * * * \\
(0.001)\end{array}$ & $\begin{array}{c}-0.013 * * * \\
(0.001)\end{array}$ \\
\hline Female & $\begin{array}{c}0.011 \\
(0.033)\end{array}$ & $\begin{array}{c}0.013 \\
(0.033)\end{array}$ \\
\hline College education & $\begin{array}{c}0.104 * * \\
(0.030)\end{array}$ & $\begin{array}{c}0.102 * * \\
(0.030)\end{array}$ \\
\hline Political knowledge & $\begin{array}{l}-0.028 \\
(0.024)\end{array}$ & $\begin{array}{l}0.157^{*} \\
(0.077)\end{array}$ \\
\hline Political knowledge ${ }^{2}$ & & $\begin{array}{c}-0.089 * * \\
(0.027)\end{array}$ \\
\hline Satisfaction with democracy & $\begin{array}{c}-0.115^{* * *} \\
(0.021)\end{array}$ & $\begin{array}{c}-0.116^{* * *} \\
(0.020)\end{array}$ \\
\hline Political efficacy & $\begin{array}{c}-0.058^{* *} \\
(0.019)\end{array}$ & $\begin{array}{c}-0.059 * * \\
(0.019)\end{array}$ \\
\hline Close to a party & $\begin{array}{c}-1.105^{* * *} \\
(0.058)\end{array}$ & $\begin{array}{c}-1.105^{* * *} \\
(0.058)\end{array}$ \\
\hline Distance to closest party & $\begin{array}{l}-0.091 \\
(0.092)\end{array}$ & $\begin{array}{l}-0.090 \\
(0.092)\end{array}$ \\
\hline Election dummies included & Yes & Yes \\
\hline$\chi^{2}$ & $2970.79 * * *$ & $2978.66^{* * *}$ \\
\hline$\tilde{\mathrm{Df}}$ & 28,078 & 28,077 \\
\hline McFadden Pseudo-R ${ }^{2}$ & 0.090 & 0.091 \\
\hline AIC & $30,019.79$ & $30,013.92$ \\
\hline Correct predictions & $73.63 \%$ & $73.72 \%$ \\
\hline $\mathrm{N}$ individuals & 28,120 & 28,120 \\
\hline $\mathrm{N}$ elections & 33 & 33 \\
\hline
\end{tabular}

Estimates of logistic regression in Stata. Dummies for election-specific fixed effects included (not shown). Standard errors are robust for 33 election-clusters in the data. Significance levels: $* \mathrm{p}<0.05 ; * * \mathrm{p}<0.01 ; * * *$ $\mathrm{p}<0.001$.

$(\ldots)$

In a next step, we go beyond dichotomizing between switchers and non-switchers and take into account the ideological distance bridged by voters switching parties. Doing so, we no longer expect curvilinear effects but a linear decrease of the distance bridged as voters' level of political knowledge increases. For the analyses, we recode the ideological distance bridged by voters in 16 categories, breaking down the continuous variable in groups of half a point on the ideological scale. Doing so reduces overdispersion somewhat, while still taking into 
account differences in the ideological distance bridged. Given that stability dominates in the sample and because among switchers most voters change to ideologically close parties the data is nevertheless still very skewed towards zero (variance of 5.98 and mean of 1.22). Adding to this skewness, the dependent variable is bounded and cannot take values less than zero (King, 1988). ${ }^{\text {iii }}$ As a consequence, assuming a poisson or negative binomial distribution are possible modeling options. After including all our independent variables, there is still a significant amount of overdispersion, which is why we present the results of negative binomial models. In essence, a negative binomial model is a Poisson regression that is extended by estimating a dispersion parameter as well (Atkins \& Gallop, 2007).

As we did for the models investigating what explains switching, for the distance of switching as well we present two models. Model 1 only includes the main effect of political knowledge. In Model 2 we test for a curvilinear effect by including both the main and the squared effect of political knowledge. Looking at the model fit statistics at the bottom of Table 4 first, as for the logit models, the explanatory power of the models is clearly very low (Nagelkerke $\mathrm{R}^{2}$ of 0.049 for both models). The significant $\alpha$-statistic indicates that a negative binomial modeling approach performs better than an alternative poisson model. For the covariates, effects are mostly in the same direction as for the logit model. First, as voters grow older, they bridge a significantly smaller distance from one election to another. There are no significant differences between male and female voters or between voters holding a college degree and voters without a college degree. The variables capturing voters' sense of political disaffection are negative and significant. As voters are more satisfied with democracy and have a higher sense of political efficacy, they bridge a significantly smaller ideological distance. Clearly, the politically disaffected are not only more likely to switch parties (as clear from Table 3), their switches are also more extreme. The effect of closeness to a party is strong and significant and indicates that voters identifying with a political party are more ideologically restricted in their vote choices. The ideological distance to the closest party then, similarly as to what we observed for party switching, is not a significant predictor of the distance bridged.

Contrary to what could be observed for the logit model, when taking into account the distance of party switching, the effect of political sophistication on switching seems to be linear. The statistical fit for both models is about the same, but when only including the main effect of knowledge indicates a negative effect of knowledge on the distance bridged. When including 
both the main and the squared effect, on the other hand, none of them reaches a conventional level of statistical significance.

Table 4. Negative binomial models of ideological distance of party switching

\begin{tabular}{|c|c|c|}
\hline & Model 1 & Model 2 \\
\hline & $\begin{array}{c}\text { B } \\
\text { (s.e.) }\end{array}$ & $\begin{array}{c}\text { B } \\
\text { (s.e.) }\end{array}$ \\
\hline Constant & $\begin{array}{c}1.749 * * * \\
(0.120)\end{array}$ & $\begin{array}{c}1.715^{* * *} \\
(0.128)\end{array}$ \\
\hline Age & $\begin{array}{c}-0.010 * * * \\
(0.001)\end{array}$ & $\begin{array}{c}-0.010 * * * \\
(0.001)\end{array}$ \\
\hline Female & $\begin{array}{l}-0.013 \\
(0.034)\end{array}$ & $\begin{array}{c}-0.012 \\
(0.034)\end{array}$ \\
\hline College education & $\begin{array}{c}0.044 \\
(0.026)\end{array}$ & $\begin{array}{c}0.044 \\
(0.026)\end{array}$ \\
\hline Political knowledge & $\begin{array}{c}-0.099 * * * \\
(0.028)\end{array}$ & $\begin{array}{l}-0.015 \\
(0.078)\end{array}$ \\
\hline Political knowledge ${ }^{2}$ & & $\begin{array}{c}-0.041 \\
(0.029)\end{array}$ \\
\hline Satisfaction with democracy & $\begin{array}{c}-0.100 * * * \\
(0.022)\end{array}$ & $\begin{array}{c}-0.100^{* * *} \\
(0.022)\end{array}$ \\
\hline Political efficacy & $\begin{array}{c}-0.069^{* * * *} \\
(0.020)\end{array}$ & $\begin{array}{c}-0.070^{* * *} \\
(0.020)\end{array}$ \\
\hline Close to a party & $\begin{array}{c}-0.899 * * * \\
(0.044)\end{array}$ & $\begin{array}{c}-0.899 * * * \\
(0.044)\end{array}$ \\
\hline Distance to closest party & $\begin{array}{c}0.126 \\
(0.069)\end{array}$ & $\begin{array}{c}0.126 \\
(0.069)\end{array}$ \\
\hline Election dummies included & Yes & Yes \\
\hline$\alpha$ & $5.656^{* * *}$ & $5.656^{* * *}$ \\
\hline$\chi^{2}$ & $1,399.31 * * *$ & $1,400.61 * * *$ \\
\hline Df & 28,077 & 28,076 \\
\hline McFadden pseudo-R ${ }^{2}$ & 0.020 & 0.020 \\
\hline Nagelkerke pseudo- $\mathrm{R}^{2}$ & 0.049 & 0.049 \\
\hline $\mathrm{AIC}$ & $70,280.73$ & $70,281.43$ \\
\hline $\mathrm{N}$ individuals & 28,120 & 28,120 \\
\hline $\mathrm{N}$ elections & 33 & 33 \\
\hline
\end{tabular}

Estimates of a negative binomial regression in Stata. Dummies for election-specific fixed effects included. Standard errors are robust for 33 election-clusters in the data. Significance levels: $* \mathrm{p}<0.05 ; * * \mathrm{p}<0.01 ; * * *$ $\mathrm{p}<0.001$.

$(\ldots)$

Taking into account the ideological distance of volatility, therefore, results seem to confirm our second hypothesis. As a voter's level of political knowledge increases, the ideological distance bridged from one election to another is significantly smaller. The level of political sophistication of a voter affects how ideologically constrained she acts in the voting booth. If 
highly sophisticated voters switch, then, they do so to parties that are relatively close ideologically. Of the dual process which is found to be at work with regard to switching in general, therefore, it is the effect of sophistication restraining change that dominates once the ideological distance bridged is taken into account as well.

Finding a linear effect for political knowledge when taking into account the ideological distance bridged by voters indicates that especially high knowledgeable voters are ideologically restrained when casting their vote. As such, the results provide an explanation for contradictory findings when investigating the link between political sophistication and volatility for within- and between-block volatility separately. Political experts seem to be more bounded by ideological considerations when casting a vote, resulting in smaller ideological switches. Dichotomizing between switchers and stable voters, a slight curvilinear effect of political knowledge on volatility is apparent, which does indicate that some level of knowledge is needed before voters consider changing parties. When conceptualizing volatility as the ideological distance voters bridge from one election to another, however, the restraining impact of political knowledge on voters' electoral choices is more clearly visible.

\section{CONCLUSION}

Voters' level of political sophistication affects whether or not voters switch parties from one election to another. Looking at voters switching parties from one election to another, switchers are not like the typical 'floating voters' described by the Columbia school scholars. Although voters with the highest level of knowledge about politics are least likely to switch, a slight curvilinear pattern is a more correct representation to describe the link between sophistication and inter-election volatility. As such, the modification of the floating voter hypothesis proposed by Converse (1962) to describe campaign volatility seems to be valid for switching between elections as well. Theory predicts a dual effect of political expertise when switching in general is looked at. Only voters with a minimum level of knowledge of politics are expected to be open to changing parties from one election to another. As voters' level of knowledge about politics increases, however, voters should become resistant to change. Our results provide evidence for this latter mechanism, it seems as if the well-developed political attitudes of the higher knowledgeable cause a resistance to change. 
Whether voters are political novices or political experts not only affects their probability of switching parties, it also has an impact on the ideological distance bridged. The higher voters' level of knowledge about politics, the more ideologically constrained the vote choice of these voters. This implies that if a political expert switches at all, it will be to a party that is ideologically very close to the party previously voted for. As a consequence, if one is interested in the effect of political sophistication on electoral volatility, one should not distinguish within- from between-block switching. Voters switching between parties of different ideological blocks and voters switching within a block of parties are most likely to be different in terms of levels of political sophistication. As a result, investigating both groups separately would blur the effect that political sophistication has on voters' likelihood of switching parties in general.

Taking into account the ideological distance bridged by voters when investigating volatility, gives us some additional insights on a number of theories on what explains volatility. In accordance to Zelle's (1995) theory of frustrated floating voters, voters who are dissatisfied with democracy and who have low levels of political efficacy are more likely to switch parties.

Obviously, the current study suffers from some important limitations. First, we look at the distance bridged by volatile voters only in terms of left and right. Although the left-right spectrum has previously been labeled a super-issue, ideally all the relevant dimensions in a party system should be taken into account for calculating the true distance between parties. Second, investigating voters who are changing parties from one election to another, we make use of cross-sectional data including a recall question. The reliance on this type of questions is likely to bias our findings, given that we expect a substantial amount of faulty recalls. Additionally, it is especially the lower sophisticated who can be expected to report false consistency in voting behaviour. All these elements, including the low level of explained variance of the models, are caveats to our conclusions. These limitations are not only relevant for this particular paper, but for electoral research in general. We are using one of the best comparative sources for electoral research available and are still limited in providing answers to what is an elementary question in political science: who changes parties between elections? Therefore one of the major conclusions of this research is that we need better data if we want to take new steps in research on volatility. Panel-data would be the most appropriate to investigate this, but current data-availability hinders doing so for a broad set of countries. 
Given the limited amount of variance in the ideological distance between parties in single countries, we can only call upon scholars of political science to engage in efforts of collecting comparative panel-data on voting behaviour. Further research, both in single countries and from a comparative perspective is needed to validate whether our results hold when using panel data and incorporating multiple ideological dimensions as well.

\footnotetext{
${ }^{\mathrm{i}}$ For the estimation sample, the three knowledge items were answered correctly by $77 \%, 62 \%$ and $34 \%$ of the respondents respectively.

${ }^{\text {ii }}$ Estimating fixed effects models comes with the cost of not allowing to investigate differences across countries in the effect of political sophistication on vote switching. To investigate this possibility we also estimated a hierarchical linear model with besides random intercepts at the election level also a random slope of the effect of political knowledge. These analyses indicated that there is virtually no variation across elections in the slope of political knowledge, indicating that the pattern observed is a general one. Results of these additional analyses are available from the authors upon request.

iii As King (1988) has shown, for data with such distributional properties, log transforming the dependent variable and estimating an OLS regression leads to biased estimates.
} 